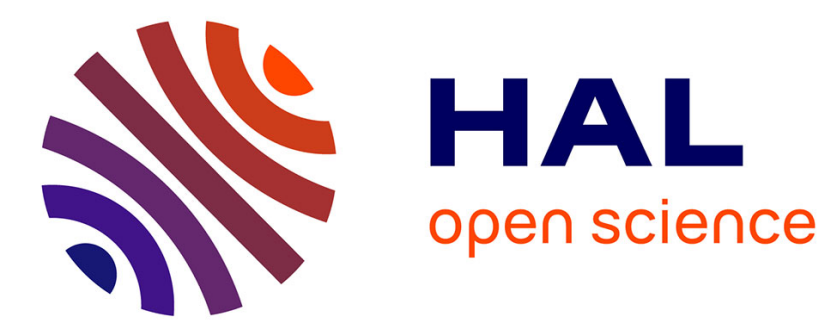

\title{
Multi-faceted particle pumps drive carbon sequestration in the ocean
}

Philip W. Boyd, Hervé Claustre, Marina Lévy, David Siegel, Thomas Weber

\section{To cite this version:}

Philip W. Boyd, Hervé Claustre, Marina Lévy, David Siegel, Thomas Weber. Multi-faceted particle pumps drive carbon sequestration in the ocean. Nature, 2019, 568 (7752), pp.327-335. 10.1038/s41586-019-1098-2 . hal-02117441

\section{HAL Id: hal-02117441 \\ https://hal.science/hal-02117441}

Submitted on 27 Nov 2020

HAL is a multi-disciplinary open access archive for the deposit and dissemination of scientific research documents, whether they are published or not. The documents may come from teaching and research institutions in France or abroad, or from public or private research centers.
L'archive ouverte pluridisciplinaire HAL, est destinée au dépôt et à la diffusion de documents scientifiques de niveau recherche, publiés ou non, émanant des établissements d'enseignement et de recherche français ou étrangers, des laboratoires publics ou privés. 
1 Multi-faceted particle pumps drive carbon sequestration in the ocean

$7 \quad$ Philip W. Boyd ${ }^{1}$ Hervé Claustre ${ }^{2}$, Marina Levy ${ }^{3}$, David A. Siegel ${ }^{4}$, Thomas Weber ${ }^{5}$

8

9 Institute for Marine and Antarctic Studies, University of Tasmania, Hobart, Tasmania, 10 Australia

$11{ }^{2}$ Sorbonne Université \& CNRS, Laboratoire d'Océanographie de Villefranche-sur-mer 12 (LOV), 06230 Villefranche-sur-Mer, France.

13 33 Sorbonne Université, LOCEAN-IPSL, CNRS/IRD/MNHN, 4 Place Jussieu, 75252 Paris

14 CEDEX 05, France.

$15{ }^{4}$ Department of Geography \& Earth Research Institute, University of California, Santa

16 Barbara, Santa Barbara, CA, 93106, USA,

$17{ }^{5}$ Department of Earth and Environmental Sciences, University of Rochester, Rochester, NY $18 \quad 14627$

Orchid \#

21 Philip Boyd http://orcid.org/0000-0001-7850-1911

Hervé Claustre 0000-0001-6243-0258

Marina Levy 0000-0003-2961-608X

David Siegel https://orcid.org/0000-0003-1674-3055 
34 The ocean's ability to sequester carbon out of contact with the atmosphere exerts an

35 important control on global climate. The biological pump drives carbon storage in the

36 deep ocean and is thought to function via gravitational settling of organic particles from

37 surface waters. However, the settling flux alone is often insufficient to balance

38 mesopelagic carbon budgets or meet the demands of subsurface biota. Here, we review additional biological and physical mechanisms that inject suspended and sinking particles to depth. Together, these "particle injection pumps” likely sequester as much carbon as the gravitational pump, closing carbon budgets and motivating further investigation of their environmental controls.

43 


\section{Introduction}

60 Open ocean waters store (sequester) carbon out of contact with the atmosphere on decadal to

61 millennial timescales, exerting a major control on global climate by regulating atmospheric

62 carbon dioxide partial pressure $\left(\mathrm{pCO}_{2}\right)^{1}$. The magnitude of ocean carbon storage is governed

63 by two well-established mechanisms that maintain a surface-to-deep ocean gradient of

64 dissolved inorganic carbon (DIC) - the biological and the solubility pumps ${ }^{2,3}$. The solubility

65 pump delivers cold, dense, DIC-rich waters to depth mostly at high latitudes, whereas the

66 biological pump globally exports particulate organic carbon (POC) from surface waters. POC

67 export is largely attributed to the gravitational settling of a subset of the particle assemblage $\mathrm{e}^{1,4}$

68 - a process we refer to as the "biological gravitational pump” (BGP).

69 The BGP is the key link between upper ocean photosynthetic carbon fixation, the sustenance

70 of mid-water biota, and carbon storage in the oceans' interior ${ }^{4,5}$, and is thought to account for

$71 \sim 90 \%$ of the vertical DIC gradient, while the solubility pump explains the remainder ${ }^{1}$. In the

72 absence of the BGP, models predict atmospheric $\mathrm{pCO}_{2}$ would be higher by nearly twofold ${ }^{6}$.

73 Contemporary and paleoceanographic observations both reveal that carbon sequestration by

74 the BGP is affected by environmental changes in light, temperature, stratification and nutrient

75 availability ${ }^{7,8}$, and can itself drive dramatic climate shifts such as glacial-interglacial cycles ${ }^{8}$.

76 Future climate projections suggest that the functioning of the BGP will be altered by ocean

77 global change $e^{7,9}$, potentially feeding back on anthropogenic climate warming ${ }^{10}$. As a

78 consequence, quantification of its functioning requires a reliable baseline of accurate

79 measurements.

80 The underlying principles of the BGP are long established ${ }^{11}$ : organic particles are continually

81 produced and recycled in sunlit surface waters, and a small fraction of these settle into the 
82 oceans' interior. The strength of the BGP is often quantified as the rate of particle "export"

83 from the euphotic zone, the surface mixed layer, or across an arbitrary horizon at $100 \mathrm{~m}^{12}$. As

84 they sink, particles undergo myriad transformations, which lead to pronounced vertical

85 attenuation of the particle flux that is often described as a power law relationship, referred to

86 as the "Martin Curve"13. The efficiency of the BGP is defined here as the time that exported

87 carbon is kept sequestered from the atmosphere within the ocean's interior. It is driven by the

88 depth scale of flux attenuation and pathways of ocean circulation that carry remineralized

89 carbon dioxide back to the surface ${ }^{14}$. Carbon is sequestered for timescales longer than a year

90 by particles that penetrate the permanent pycnocline (beneath the wintertime mixed layer)

91 and up to centuries by those that reach deep water masses (generally $>1000 \mathrm{~m}$ ). Together, the

92 strength and efficiency of the BGP determine the total quantity of carbon sequestered

93 biologically in the ocean interior.

94 Recently, analyses of global and regional ocean carbon budgets have identified conspicuous imbalances (i.e., two to three-fold less storage) when BGP export fluxes are compared with

96 those derived from geochemical tracers ${ }^{15,16}$, highlighting the need to reassess the pathways

97 that contribute to carbon storage. Furthermore, rates of site-specific particle export appear to

98 be insufficient to meet the carbon demand of mid-water life (termed mesopelagic biota) by

99 two-to three-fold ${ }^{17-20}$, but in one study can be balanced using community respiration ${ }^{18}$. There

100 is considerable debate over the reasons for these carbon deficits, ranging from biases inherent

101 in observational technologies ${ }^{17,21}$ to the potential role of other carbon (dissolved and/or

102 particulate) delivery mechanisms to deep waters ${ }^{16,22,23}$. Traditionally, the biogeochemical

103 functioning of the BGP has been evaluated from quasi one-dimensional (1D) observations of

104 particle flux (Box 1), and extrapolated using Earth System Models (ESMs, parameterised

105 with observations ${ }^{24-26}$ ) and/or remote-sensing observations ${ }^{26}$. This approach cannot capture 
more complex mechanisms of carbon export that are highly variable in space and time (Box 1), potentially resulting in the reported carbon budget deficits.

Multiple lines of research have revealed the importance of additional export pathways, physically (e.g. subduction) and/or biologically (e.g. large mesopelagic migrators) -mediated, that inject particles to depth, termed here Particle Injection Pumps (PIPs) ${ }^{23,27-30}$. These mechanisms can potentially export all particle classes to depth, and thus challenge the conventional view of gravitational sinking as the dominant downward pathway for particles into the oceans' interior. The characteristics of PIPs fundamentally change our understanding of biological carbon sequestration: first, PIPs can animate particle transport spatially into three dimensions (3D), in contrast with the BGP where the vertical dimension is predominant (1D); second, global estimates of PIP carbon fluxes are significant relative to those for the $\mathrm{BGP}^{27,28}$, and third, these mechanisms cannot be readily quantified using the traditional toolbox applied to investigate the BGP (Box 1). Overall, the PIPs will increase the strength of the biological pump beyond estimates based on gravitational flux alone, and can change its efficiency by altering the depth of carbon export.

The fate of exported carbon following its delivery to depth has also proven more complex and heterogeneous than previously recognized. Particle flux attenuation is now known to vary systematically in space ${ }^{14,31,32}$ and time ${ }^{33}$, suggesting the traditional empirical view ${ }^{13}$ must be replaced by a mechanistic one that considers particle composition and architecture, microbial metabolism, and transformation processes ${ }^{17}$.

Together, these developments stand to reshape our understanding of particle transport and remineralisation in the oceans' interior. Here, for open ocean systems we review: the mechanisms, rates, and depths of particle injection by each PIP; the potential for each mechanism to close observed deficits in ocean carbon budgets; and the corresponding 
remineralisation depths of exported POC in the deep ocean. We finish by outlining future research directions needed to synthesize these developments into a new mechanistic, fourdimensional (4D) view of carbon export and sequestration. The review does not detail the important role of dissolved organic carbon subduction ${ }^{22,23}$, nor cover the dark microbial carbon pump ${ }^{34}$ or chemolithotrophy ${ }^{35}$ which have been reviewed elsewhere (S-Table 1).

\section{Particle injection pump mechanisms}

PIPs differ in their mechanisms, temporal-spatial scales (Fig. 1, Fig. 2a), and/or geographical extent, but have common features: i) they can act on all particles from suspended to sinking (Fig. 1); ii) they typically inject particles below the euphotic zone (i.e., the export depth for the BGP), potentially reaching depths $>1000 \mathrm{~m}^{28-30}$ depending on the injection mechanism (Fig. 1, Fig. 2b); iii) they occur concurrently with the BGP but cannot be measured with techniques developed to quantify gravitational settling ${ }^{13,32}$ (Box 1); iv) their dynamic nature (i.e., physical transport ${ }^{23,27,28}$ or patchiness of animal distributions ${ }^{30}$ ) means that the interplay between their vertical and horizontal vectors and temporal scales varies significantly (Fig. 1). Hence, a 4D sampling framework is required to constrain them (Box 1). The main characteristics of each PIP are elucidated below.

Particle export driven by physical subduction includes several processes driving the vertical transport of near-surface particles that act on different space/time scales: subduction caused by mixed-layer shallowing (termed the mixed-layer pump ${ }^{29,36}$ ); subduction by large-scale (100-1000 km) circulation (termed the large-scale subduction pump) ${ }^{23}$; and subduction by mesoscale (10-100 km) to submesoscale (1-10 km) frontal circulation (termed the eddysubduction pump ${ }^{23,27,28}$ ). 
153 Carbon export by the mixed-layer pump is driven by biological accumulation of particles

154 throughout the spring/summer growth season, which are then diluted to the depth of the

155 mixed layer during winter, and left in the oceans’ interior during early spring stratification

156 (Box 1). This pump operates on wide-ranging time-scales from days/weeks ${ }^{37}$ to seasons ${ }^{29,37}$,

157 predominantly in mid and high latitude regions characterised by strong seasonal variability in

158 mixed-layer depth (Fig. 2a). Although these concepts are long-established ${ }^{36}$, only recently

159 have they been scrutinised in detail using advances in optical profiling (BGC-Argo) floats

160 and satellite particle proxies to track particle accumulation rates in relation to changes in

161 surface mixed-layer depth (Box 1).

162 The large-scale subduction pump is a 3D advective mechanism directed from the seasonal 163 mixed-layer into the oceans' interior, driven by Ekman pumping and horizontal circulation 164 across a sloping mixed-layer ${ }^{38}$. Subduction rates were first estimated for the North Atlantic ${ }^{39}$, 165 and then globally using data-assimilating models ${ }^{40}$. The wide-ranging subduction rates (1-100 $166 \mathrm{~m} /$ year $)^{39,40}$ are small relative to BGP particle settling rates ${ }^{11,12}$, but subduction occurs over 167 large regions of the global ocean boosting the magnitude of carbon delivery to depth.

168 The frontal-associated eddy-subduction pump subducts particle-rich surface waters on 169 timescales of days and across spatial scales of 1-10 km, driven by strong vertical circulation 170 associated with fronts and eddies ${ }^{27,28,41-44}$. Gliders are now used to map 3D dynamic eddying

171 flow fields (Box 1), finding evidence for penetration of high particle stocks (co-located POC 172 and chlorophyll indicative of viable phytoplankton) from the spring bloom, conspicuous as 173 distinct filaments at 100-350 m depth at the eddy periphery ${ }^{28}$ (Box 1). Mapping revealed the 174 co-location of high POC filaments and negative vorticity to depths near the permanent 175 pycnocline ${ }^{28}$, and the mechanism is supported by high-resolution simulations in which eddy 176 subduction of particles is a recurring feature ${ }^{45-48}$. The strength of the eddy-subduction pump 
177 is governed by the vigour and penetration of the vertical circulation, in conjunction with local 178 POC stocks over the frontal area ${ }^{27,49}$. Eddy subduction rates span 1-100 $\mathrm{m} \mathrm{d}^{-1}$ (c.f. 20 to > $179100 \mathrm{~m} \mathrm{~d}^{-1}$ for the $\mathrm{BGP}^{11,12}$ ) depending on the eddy or frontal structure. Modelling indicates 180 that these subducted particles are remineralised more rapidly (i.e., at relatively shallow depths) 181 relative to gravitationally-sinking particles ${ }^{27}$.

182 The concept for the 'mesopelagic migrant pump' is based on long-established observations of 183 diurnal vertical migration ${ }^{50}$ (Box 1). This pump extends the remineralisation scale by 184 injecting particles to greater depth before decomposition begins ${ }^{51,52}$, as determined by gut 185 retention time of migrating animals $\mathrm{s}^{51-53}$ and the depth of their migration (typically $\sim 400 \mathrm{~m}^{53}$ ).

186 The injected particles are zooplankton faecal pellets with sinking rates of $10-100$ 's $\mathrm{m} \mathrm{d}^{-1}$ (ref.

187 51), faster than loosely-packed organic aggregates settling from the surface ${ }^{11,12}$, and will 188 penetrate deeper in the water column before remineralisation. This pump therefore influences 189 all important facets of the particle flux that govern carbon sequestration - total export rate, 190 depth of peak flux, and flux attenuation depth scale.

191 Diurnal vertical migration results in active subsurface transport and carbon sequestration, and 192 is usually reported for mesozooplankton and often included in BGP estimates ${ }^{51}$. However, 193 vertical migration by larger mesopelagic carnivorous organisms (from greater daytime depths 194 than mesozooplankton) are not sampled by conventional BGP approaches ${ }^{52,54}$. Targeted 195 studies (Box 1) have quantified this pump driven by large mesopelagic migrant carnivores in 196 the Pacific ${ }^{54}$, and other regions (S-Table 1). The underlying mechanism is upward migration 197 to graze mesozooplankton ${ }^{54}$ followed by rapid (hours) downward migration ${ }^{53}$, with 198 respiration (release of $\mathrm{CO}_{2}$ ), exudation, and defecation (release of POC/DOC) ${ }^{51,55}$ often 199 below the permanent pycnocline ${ }^{56}$, at depths up to 600m (Box 1). 
200 Trawl surveys suggest that $\sim 50 \%$ of mesopelagic organisms migrate, ranging regionally

201 between $20-90 \%$ depending on temperature, turbidity and oxygen concentrations ${ }^{54,56}$. The

202 carbon sequestration rate by this pathway is governed by the metabolic transfer efficiency of

203 migrators, and particles are injected at their residence depth, often at the upper boundary of

204 oxygen minimum zones where their respiration intensifies oxygen depletion ${ }^{53}$.

205 Active transport by vertically-migrating metazoans can also occur on longer timescales (Box

206 1). For example, in high latitude regions the winter hibernation of copepods (members of the

207 mesozooplankton) at depths between 600-1400m gives rise to a so-called 'seasonal lipid

208 pump $^{30}$ : during hibernation, they catabolise carbon-rich lipids accumulated during summer in

209 upper layers and thereby shunt carbon (but not nitrogen and phosphorus) below the

210 permanent pycnocline ${ }^{30}$. The strength of the seasonal lipid pump is governed by copepod

211 abundance, size and temperature, which together control their respiration rate and help

212 explain the existence of carbon flux hotspots (i.e. patchiness) ${ }^{30}$.

213 Another vertical export mechanism that operates on seasonal migration timescales is

214 mortality at depth of hibernating zooplankton particularly in high latitude regions ${ }^{57,58}$,

215 sequestering carbon to depths $>500 \mathrm{~m}$ depth. Global extrapolation of seasonal lipid pump

216 fluxes, along with the over-wintering mortality flux is problematic due to difficulties in

217 sampling and generalizing across distinct regional mechanisms ${ }^{30}$ (S-Table 1).

\section{The potential for double accounting}

220 The export flux from the BGP is mediated by sinking particles, whereas PIPs can provide

221 additional pathways for all particle classes, from suspended to sinking, to exit the surface

222 ocean (Fig. 1). Thus, there is potential overlap between particles delivered from the surface

223 ocean to depth via the BGP and by injection from PIPs. Such overlap - termed here as 
'double-accounting' - may occur where particles associated with the BGP and a PIP are

difficult to distinguish and hence could be attributed to more than one pump (Fig. 1). At

depth, transformations such as aggregation alter particle characteristics, including size and

sinking rate, and hence particles injected by the PIPs can join the sinking flux usually attributed the BGP (Fig. 1). A further factor that introduces overlap between the BGP and PIPs results from the inclusion, for historical reasons ${ }^{59}$, of one component of the mesopelagic migration pump (diurnal migration by mesozooplankton) into the 1D sampling framework of the BGP, while other components (e.g. patchier diurnal migration by larger mesopelagic carnivores $^{5}$ ) are not. Hence double-accounting can confound our understanding of the relative importance of PIPs to ocean carbon storage.

234 Is it possible to tease apart these areas of overlap? Forty years study of the BGP has 235 uncovered a complex biogeochemical system with multiple drivers and distinguishing 236 characteristics ${ }^{11,60}$. This body of research helps to frame the differences and similarities 237 between particles delivered to depth by PIP’s and those settling via the BGP. Each PIP is 238 distinct with respect to its combination of injected particle type (suspended cells to faecal 239 pellets of large mesopelagic migrants), the timing and depth of injection (Fig. 2a-b), and 240 associated particle transformations (aggregation/disaggregation) ${ }^{11,12,61}$. Additionally, the 241 subsurface “fate” of particles (i.e. where they remineralize), which determines the longevity 242 of carbon sequestration, is driven by the complex interplay between these properties and 243 transformations ${ }^{12,60,61}$ : Particle composition and architecture set their sinking speed, while 244 myriad processes that are biologically- (microbes/zooplankton) and physically-mediated 245 (fragmentation/ disaggregation) ${ }^{12,62-64}$ decompose and repackage them over depth (Fig. 1). 246 Therefore, particle fate provides another avenue to distinguish the contributions of PIPs from 247 the BGP. 
248 To date, evidence on the subsurface fate of injected particles has been largely indirect ${ }^{27,28,49}$.

249 Surveys of eddy-subduction pumps suggest that injected particles may be remineralised at 250 depths $<200 \mathrm{~m}$, based on ammonium peaks ${ }^{49}$, time-series of biogeochemical gradients ${ }^{28}$, or

251 particle modelling studies ${ }^{27}$. In the NE Atlantic, reported high rates of particle

252 remineralisation (glider-based biogeochemical gradients) must be reconciled with concurrent

253 evidence of coincident, coherent chlorophyll plumes at depths $>300$ m indicative of

254 subducted viable phytoplankton ${ }^{28}$. This glider-based time-series reveals pronounced

255 patchiness ${ }^{28}$ suggesting that inference of the fate of injected particles even from state-of-the-

256 art observations is challenging.

257 Better constraining the contribution of each PIP to mesopelagic carbon budgets will require

258 characterisation of the injected particle assemblage and their transformations during

259 downwards transport ${ }^{12,65-68}$. Particle aggregation in PIPs may be driven by

260 convergence/subduction ${ }^{69-70}$ and/or differential sinking ${ }^{65,67}$, potentially leading to altered

261 modes of subsurface transport (Fig. 1). BGC-Argo profile observations allow quantification

262 of the size, type, seasonal succession, and penetration depths of particles injected by the

263 mixed-layer pump ${ }^{36}$ - properties which have the potential to differentiate them from fast-

264 sinking particles (i.e., BGP) whose distinctive 'spiky' bio-optical signature is readily detected

265 using multiple sensors ${ }^{71}$ (S-Figs. 2 and 3). Advances in bio-optics are already making cryptic

266 signatures associated with slow-sinking particles and zooplankton vertical migration less

267 opaque, lessening the possibility of double-accounting. Such double-accounting may be

268 avoided through the identification of unique characteristics of pumps including seasonality

269 (Fig. 2a), distinctive regional features ${ }^{30}$, or multi-variate oceanographic diagnostics ${ }^{72}$. 


\section{Carbon sequestration potential}

273 The potential carbon sequestration by each PIP can be quantified as the product of their

274 carbon injection rate and their sequestration timescale, i.e. time until remineralised carbon is

275 returned to the surface (see Supplementary Methods). This timescale is determined both by

276 the injection depth of particles and their eventual fate, i.e. the degree to which they sink or

277 circulate through the ocean before remineralising to $\mathrm{CO}_{2}$. In general, deeper particle injection

278 and rapid sinking translates to longer carbon sequestration because the "passage time" from

279 the ocean interior to the surface increases with depth (Fig. 2b). Here, we assemble prior

280 estimates of carbon injection rate and depth (S-Table 1), along with new modelling

281 projections (Fig. 2), to estimate carbon sequestration by each PIP and assess their

282 significance relative to the BGP.

283 Some targeted studies provide concurrent estimates of carbon injection by individual PIPs

284 and the $\mathrm{BGP}^{27,28}$, whereas others ${ }^{30,54,57,58}$ facilitate comparison of regional-scale PIP fluxes

285 with independent estimates of the BGP. Both approaches reveal that PIPs each have the

286 potential to contribute significant rates of POC export. The reported upper bounds of global

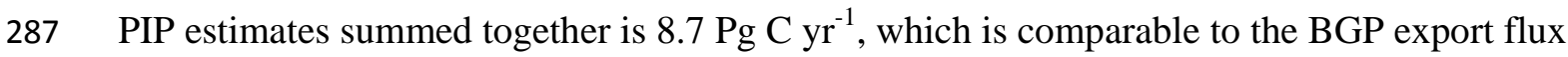

288 (Table S1). This comprises 1.1-2.1 $\mathrm{Pg} \mathrm{C} \mathrm{yr}^{-1}$ for the large-scale/mesoscale physical pumps

289 (also includes $\mathrm{DOC}^{22,23}$ ), and 0.25-1.0, 0.9-3.6 and (-0.09) to $2.0 \mathrm{Pg} \mathrm{C} \mathrm{yr}^{-1}$ from the lipid

290 seasonal, mesopelagic migration, and eddy-subduction pumps, respectively (Fig. 2c). Thus,

291 their cumulative contribution may be as much as $~ 40 \%$ of total particle export (i.e.,

292 BGP+PIPs) suggesting considerable potential to resolve the imbalances reported for

293 mesopelagic carbon demand ${ }^{17}$, between nutrient and carbon export budgets ${ }^{15}$, and to lessen

294 the variability between model estimates of global carbon sequestration (S-Table 1). 
295 We estimated the sequestration timescales for each PIP based on the "passage time" from the

296 injection depth to the surface in an observationally-constrained ocean circulation model ${ }^{14}$.

297 Particles injected at the depth of the wintertime mixed-layer by the large-scale physical

298 pumps (mixed-layer and subduction) result in sequestration for 25-100 years, assuming

299 subduction occurs before re-entrainment next winter. In turn, deeper injection by the eddy

300 subduction pump (up to $450 \mathrm{~m}$ ), mesopelagic migration pump (up to $600 \mathrm{~m}$ ), and seasonal

301 lipid pump (up to $1400 \mathrm{~m}$ ) translates to sequestration timescales up to 150, 250, and 500

302 years respectively (Fig. 2b). These timescales will increase if it is assumed that sinking rather

303 than suspended particles are injected, which remineralise deeper than the injection horizon

304 (see Supplementary Methods).

305 Given the wide-ranging estimates of carbon injection rate (Fig. 2c) and depth (Fig. 2b) for each PIP, oceanic carbon sequestration by these mechanisms cannot be estimated with precision (Fig. 2d). However, choosing central values from the reported ranges of each property allows a first order comparison between PIPs and the BGP. The mesopelagic migration pump emerges as the most significant PIP, potentially storing $\sim 60 \%$ as much carbon as the BGP in the ocean interior if large, sinking particles (i.e. faecal pellets) are injected. The C storage potential of the seasonal lipid, eddy-subduction and large subduction pumps are $\sim 20 \%, 10 \%$ and 5\% of the BGP respectively, assuming each injects suspended particles. The latter small net value is due to offsetting of subduction by strong obduction

314 (upward transport of water parcels) in the equatorial oceans ${ }^{39}$. Based on these central values 315 (Fig. 2d), it is likely that the reservoir of respired carbon in the ocean interior contributed by 316 the PIPs approaches that contributed by the BGP, and may therefore help to close global317 scale mesopelagic carbon budgets ${ }^{15,16}$. 


\section{Tracer constraints on the fate of exported carbon}

320 Oceanic carbon sequestration by the BGP and wide-ranging biophysical mechanisms that

321 inject biogenic particles to depth depends critically on the fate of exported carbon (Fig. 2).

322 However, at present tracing the remineralisation of particles (regardless of their export

323 pathway) as they settle and circulate through the global ocean remains a logistical challenge,

324 due to the difficulties of deep-water particle sampling. Recently, new methods have used 3D

325 ocean data assimilation models to leverage geochemical "remineralisation tracers" including

326 oxygen and nutrients. These tracers integrate particle remineralisation signatures over long

327 timescales, and their global distributions are characterised by orders of magnitude more

328 observations than are available for particles ${ }^{16,31,73}$. Two distinct approaches have been applied.

329 The first diagnoses remineralisation rates directly from phosphate accumulation along

transport pathways in a circulation model, and reconstructs particulate flux profiles required

to explain the global distribution of remineralised phosphate ${ }^{31}$. The second assimilates

geochemical and satellite data into mechanistic biogeochemical models to optimise key

particle flux parameters, yielding mechanistic insights while leveraging the observations less

334 directly $^{73}$.

Both approaches have yielded similar results and provide evidence for regional variability in particle flux attenuation, with the flux attenuating slowly at high latitudes and quickly in

subtropical gyres, while the tropics lie between these two extremes (Fig. 3a). These

simulations reveal that carbon exported from high latitude and tropical surface waters is sequestered longer in the oceans' interior than carbon exported in the oligotrophic gyres

(Figure 3b), with important implications for feedbacks between the particle export and global climate. Atmospheric $\mathrm{pCO}_{2}$ is likely more sensitive to past changes in high latitude export than previously recognised ${ }^{8}$, and the future expansion of subtropical habitats ${ }^{9}$ may result in less efficient (although not currently quantifiable) carbon sequestration in a warming world. 
344 Regional variations in particle flux attenuation have largely been interpreted in terms of the 345 balance between decomposition and sinking rates ${ }^{32}$. A likely explanation for the diagnosed 346 latitudinal pattern is the temperature-dependent metabolism of heterotrophs responsible for 347 particle decomposition ${ }^{32,73}$, although variations in particle size and/or ballast are valid 348 alternatives ${ }^{73}$. There may also be a secondary effect of oxygen, with decomposition slowing 349 in anoxic zones ${ }^{73,74}$, and even hypoxic waters due to anaerobic microenvironment formation 350 in particles ${ }^{75}$.

351 To some degree, model-derived particle flux profiles may also reflect the relative magnitude 352 of different export pathways (PIPs and BGP), which vary in the injection depth and nature of 353 particles they supply, since geochemical tracers integrate the effects of all export mechanisms. 354 Deep injection by PIPs would result in slower flux attenuation over depth, whereas injection 355 of suspended particles that remineralise shallower in the water column would be diagnosed as rapid flux attenuation. Predicting future changes in ocean carbon sequestration will require a 357 better understanding of the contribution of injection versus remineralisation processes to 358 sequestration efficiency (Fig. 3b), given the different environmental sensitivity of these 359 processes.

360 The need for prediction motivates development of new techniques to distinguish particle flux associated with the BGP and each PIP. Particle stoichiometry (i.e., C:N:P) may be central to identifying particular mechanisms that decouple their export. For example, diagnosing oxygen consumption between 500-1500 m (depth of zooplankton hibernation) without concomitant nutrient accumulation would point to carbon export by the seasonal lipid pump ${ }^{30}$.

365 Alternatively, diagnosing seasonal cycles of nutrient accumulation and oxygen consumption 366 rates would help distinguish remineralisation of particles exported by physical pumps versus 367 particle settling, which should exhibit distinct seasonality (Fig. 2a). This approach may soon 
be possible given the burgeoning spatial/temporal resolution of tracer data provided by BGCArgo floats (S-Figure 1), and emerging float sensor technology (S-Table 2).

\section{Extrapolation - towards a 4D view of particle export}

Improving the accuracy of the initial estimates of the magnitude of carbon sequestration presented in Figure 2d requires the development of a 4D picture of particle flux and storage in the oceans' interior. It is clear from our synthesis of PIP mechanisms that multiple scales, from sub-mesoscale to basin, must be accommodated if PIPs are to be assembled, first spatially and then temporally, into a complete 4D picture. Again, lessons on how to approach such upscaling can be gleaned from BGP research which imprinted both spatial and seasonal signatures (satellite remote-sensing/modelling) ${ }^{26}$ onto short-term (days-weeks) observations taken at specific sites (Box 1). The timescales and lifetimes of features such as submesoscale eddies/fronts or seasonal mesopelagic export signatures (Fig. 2a) must be characterized to define the temporal footprint of each PIP and move towards a 4D viewpoint. This framework must be linked to the seasonality of pelagic particle production to assess if there is distinctive period for the subduction of significant stocks of these upper ocean particles (Fig. 2a). For example, it is well-established that submesoscale dynamics are strongly seasonal, with stronger and deeper penetration during winter than summer ${ }^{76}$.

Some published approaches towards extrapolating PIP's globally, and to climatological time scales, are outlined in S-Table 1. The identification of the specific drivers of each PIP mechanism should help improve modelling and hence extrapolation. We advocate the utility of explicitly incorporating the different PIP mechanisms into predictive, mechanistic models as a means to extrapolate PIPs into 4D. In the case of the extrapolation of the submesoscale eddy subduction PIP, increasing the model grid resolution to incorporate these features is 
392 necessary and is now achievable in regional configurations ${ }^{77,78}$. In contrast, other physically-

393 mediated PIPs such as the large-scale subduction and mixed-layer pumps are already

394 represented in global models, and so their extrapolation requires the development of

395 diagnostics to enable the simulated POC/DOC distributions to be better evaluated against

396 observations ${ }^{23}$. At present, the biologically-mediated PIPs are not incorporated into state-of-

397 the-art biogeochemical models $s^{9,14,31,77,78}$. While simulating animal behaviour at the global

398 scale remains a grand challenge in ocean modelling, simple parameterisations have been

399 developed to predict the geochemical effect of the mesopelagic migrant pump ${ }^{6}$, which might

400 be further expanded to incorporate hibernation and therefore the seasonal lipid pump. It is

only very recently that diel vertical migration has been incorporated for the first time in a

402 global ocean general circulation model and used to estimate the associated flux of carbon at

403 the global scale (see Aumont et al. in S-Table 1). Although promising, this approach remains

404 challenging because it is based on a computationally-intensive, end-to-end ecosystem model

405 in which all trophic levels from phytoplankton to top predators interact.

407 Transforming our view of ocean carbon export

408 Our synthesis of physically- and biologically-mediated PIPs reveals that they are directly

409 transporting significant stocks of biogenic particles to depth, of a cumulative magnitude that

410 may be equivalent to the carbon storage of the BGP. The potential of PIPs to make a major

411 contribution to the ocean carbon budget must now be explored in more detail, commencing

412 with those PIPs that are most likely to contribute to carbon sequestration. Synthesising

413 estimates of particle export, injection depth, and circulation timescales reveals that the

414 mesopelagic migrant pump has the greatest potential to contribute to carbon sequestration,

415 followed by the seasonal lipid pump and the various physical pumps (Fig. 2d). In the case of 
416 the seasonal lipid pump, its geographical realm of influence is already established ${ }^{30}$, whereas

417 less is known about the regional contributions of the mesopelagic migrant pump 5 .

418 For all PIPs, the most pressing research issue - needed to address double-accounting issues

419 and improve estimates of carbon sequestration - is to better understand the mechanisms of

420 particle transformations ${ }^{17,65-68}$ (Fig. 1) within a 4D framework. Specifically, the fate of

421 exported particles between their injection depth and the permanent pycnocline remains poorly

422 constrained. A first step will be improved particle characterisation, in particular the ability to

423 distinguish zooplankton from other particle types, and to aggregate Particle Size Distribution

424 (PSD) profiles through the development and application of new sensors (S-Table 2). Future

425 development of acoustic and imaging technologies ${ }^{79}$ must be deployed on a range of

426 platforms from ships (i.e., calibration) to an array of long-lived (i.e., years), geographically-

427 diverse BGC-Argo floats. These developments towards improving particle characterisation

428 will reduce the likelihood of double-accounting. Moreover, the alignment of BGC-Argo

429 deployments (Box 1) with the characteristic space and time scales of PIPs will enable better

430 quantification of the role of patchiness in driving observed local/regional hotspots in

431 biological PIPs ${ }^{30,54,56}$. In time, following the development and testing of a Coastal-Argo

432 platform, they can also be deployed to coastal and shelf seas to explore the role of PIPs in

433 these regions (S-Table 2).

434 The way forward in refining estimates of the contribution of PIPs in closing the ocean carbon

435 budget $^{15-17}$ also requires leveraging advancements in ocean biogeochemical modelling.

436 Models are valuable testbeds to probe the sensitivity of carbon storage mechanisms, and

437 guide future observations. For example, model sensitivity analyses point to the pivotal role

438 of PSD in determining the fate of exported $\operatorname{carbon}^{31,73}$, but the processes that set the PSD of

439 exported particles and its evolution over depth remain crudely parameterized. Developing

440 robust models of particle transformations between multiple size classes, and incorporating 
441 them into general circulation models, will allow us to trace the fate of particles injected by

442 different PIPS and dissect their contribution to carbon sequestration, while avoiding double-

443 accounting issues.

444 Inverse methods that can assimilate PSD fields from new BGC-Argo technologies ${ }^{80}$ will

445 allow models to "learn" from the data, further refining them to best reflect the real ocean.

446 Furthermore, downscaling of physical models is essential to simulate the locations of PIP

447 injections in support of observational programmes such as high resolution altimetry ${ }^{81}$, and the

448 integration of detailed particle transformations into submesoscale models ${ }^{82}$.

449 To transform the comprehension of particle export from one- to three- and eventually four-

450 dimensions, machine learning approaches ${ }^{83}$ will need to be employed, which can be trained to

451 predict unknown variables such as particle flux from better sampled variables. Approaches

452 like artificial neural networks ${ }^{84}$, will enable and enhance the upscaling of local/regional

453 datasets needed to provide more robust extrapolation ${ }^{85,86}$ to depth, regionally, and annually of

454 each PIP. This upscaling is essential to refine estimates of the contribution of each PIP to

455 carbon sequestration. BGC-Argo datasets will also eventually be combined with new satellite

456 products such as hyperspectrally-resolved ocean colour observations of biology processes ${ }^{87}$

457 and submesoscale characterisation of sea level using high-resolution altimetry ${ }^{81}$.

458 Satellite and water-column remote-sensing, along with targeted process studies, will yield

459 expansive datasets that can be assimilated into regional and global models of ever increasing

460 realism and resolution. Together, these approaches will lead towards a robust, four-

461 dimensional view of carbon sequestration by the ocean's multi-faceted bio-physical particle

462 pumps. 
465 Acknowledgements

466 The authors thank five anonymous reviewers for improving the manuscript. PWB was

467 primarily supported by the Australian Research Council through a Laureate (FL160100131),

468 and this research was also supported under Australian Research Council's Special Research

469 Initiative for Antarctic Gateway Partnership (Project ID SR140300001). HC acknowledges

470 the support of the European Research Council (remOcean project, grant agreement 246777)

471 and of the Climate Initiative of the BNP Paribas foundation (SOCLIM project). ML was

472 supported by CNES and by the ANR project SOBUMS (ANR-16-CE01-0014). DAS

473 acknowledges support from the National Aeronautics and Space Administration as part of the

474 EXport Processes in the global Ocean from RemoTe Sensing (EXPORTS) field campaign -

475 grant 80NSSC17K0692. TW was supported by NSF grant OCE-1635414. Co-authors, HC, 476 ML, DS and TW contributed equally to this Review.

477

478

479

480

481

482

483

484

485

486

487

488

489

490

491

492

493

494

495

496

497

498 
500 1Sarmiento, J. L. \& Gruber, N. (2006). Ocean Biogeochemical Dynamics. (Princeton

501 University Press, 2006).

502 2Volk, T., and M. Hoffert (1985). Ocean carbon pumps: Analysis of relative strengths and

503 efficiencies in ocean-driven atmospheric $\mathrm{CO}_{2}$ changes, in The Carbon Cycle and

504 Atmospheric $\mathrm{CO}_{2}$ : Natural Variations Archean to Present, Geophys. Monogr. Ser., vol. 32,

505 edited by E. T. Sundquist and W. S. Broecker, pp. 99-110, AGU, Washington, D. C.

506 3McKinley GA, Pilcher DJ, Fay AR, Lindsay K, Long MC, Lovenduski NS. (2016).

507 Timescales for detection of trends in the ocean carbon sink. Nature 530:469-72

508 4Buesseler, K. O., Lamborg, C. H., Boyd, P. W., Lam, P. J., Trull, T. W., and co-authors

509 (2007). Revisiting carbon flux through the ocean's twilight zone through the ocean's twilight

510 zone. Science, 316, 567-570. doi: 10.1126/science.1137959.

511 5Irigoien, X. et al. (2014). Large mesopelagic fishes biomass and trophic efficiency in the

512 open ocean. Nat. Commun. 5, ncomms4271.

513 6Maier-Reimer E., U. Mikolajewicz, A. Winguth (1996). Future ocean uptake of $\mathrm{CO}_{2}$ :

514 interaction between ocean circulation and biology. Climate Dynamics, 12, 711-721.

515 7Bopp, L., et al. (2013), Multiple stressors of ocean ecosystems in the 21st century:

516 Projections with CMIP5 models, Biogeosciences, 10, 6225-6245.

517 8Martinez-Garcia, A. et al. (2014). Iron fertilization of the Subantarctic Ocean during the last 518 ice age. Science 343, 1347-1350.

519 9Moore J.K. et al. (2018) Sustained climate warming drives declining marine biological

520 productivity. Science, 2018; 359 (6380): 1139 DOI: 10.1126/science.aao6379

521 10Bernardello R. et al. (2015) Response of the ocean natural carbon storage to projected

522 twenty-first-century climate change J of Climate DOI: 10.1175/JCLI-D-13-00343.1

523 11Boyd, P. W. \& Trull, T. W. (2007). Understanding the export of biogenic particles in

524 oceanic waters: Is there consensus? Progress in Oceanography, 72(4), 276-312. doi:

525 10.1016/j.pocean.2006.10.007

526 12Buesseler, K.O., and Boyd, P.W. (2009). Shedding light on processes that control particle

527 export and flux attenuation in the twilight zone of the open ocean. Limnol. Oceanogr. 54,

528 1210-1232.doi:10.4319/lo.2009.54.4.1210

529 13Martin, J., G. Knauer, D. Karl, and W. Broenkow (1987), VERTEX: Carbon cycling in the 530 northeast Pacific, Deep Sea Res., Part A, 34, 267-285.

531 14DeVries, T., F. Primeau, and C. Deutsch (2012). The sequestration efficiency of the 532 biological pump, Geophysical Research Letters, 39, doi:10.1029/2012GL051963.

533 15Emerson, S. (2014) Annual net community production and the biological carbon flux in the 534 ocean. Global Biogeochemical Cycles 28, 1-12, doi:10.1002/2013GB004680 
16Schlitzer, R. (2002) Carbon export fluxes in the Southern Ocean: results from inverse modeling and comparison with satellite based estimates, Deep-Sea Research II, 49, 16231644.

17Burd, A. B. et al. (2010). Assessing the apparent imbalance between geochemical and biochemical indicators of meso- and bathypelagic biological activity: What the @\$\#! is wrong with present calculations of carbon budgets? Deep-Sea Res. Part II Top. Stud. Oceanogr. 57: 1557-1571. doi:10.1016/j.dsr2.2010.02.022

\section{This paper reviewed the (lack of) progress on constraining mesopelagic carbon budgets,} and advocated new approaches to tackle this issue.

18Giering, S. L. et al. (2014). Reconciliation of the carbon budget in the ocean's twilight zone. Nature 507, 480-483. doi: 10.1038/nature13123

\section{This paper presented one of the few balanced mesopelagic carbon budgets by assessing} community respiration versus carbon demand.

19Steinberg, D.K., B.A.S. Van Mooy, K.O. Buesseler, P. W. Boyd, T. Kobari, and D.M. Karl (2008). Bacterial vs. zooplankton control of sinking particle flux in the ocean's twilight zone. Limnol. Oceanogr. 53: 1327-1338.

20Reinthaler, T. et al. (2006). Prokaryotic respiration and production in the meso- and bathypelagic realm of the eastern and western North Atlantic basin. Limnol. Oceanogr. 51: 1262-1273.

21Boyd, P.W., McDonnell, A., Valdez, J. (2015) RESPIRE: An in situ particle interceptor to conduct particle remineralization and microbial dynamics studies in the oceans' Twilight Zone. Limnology and Oceanography-Methods Volume: 13s: 494-508.

22Hansell D.A., Carlson C.A., Repeta D.J., Schlitzer R., (2009). Dissolved organic matter in the ocean. Oceanography 22:52-61.

23Lévy, M., Bopp, L., Karleskind, P., Resplandy, L., Ethé, C., \& Pinsard, F. (2013). Physical pathways for carbon transfers between the surface mixed layer and the ocean interior. Global Biogeochemical Cycles, 27(4), 1001-1012. http://doi.org/10.1002/gbc.20092.

24Henson, S. A., Yool, A., \& Sanders, R. (2015). Variability in efficiency of particulate organic carbon export: A model study. Geophysical Res. Lett., 29, 33-45.

http://doi.org/doi:10.1002/2014GB004965

25Aumont, O., Van Hulten, M., Roy-Barman, M., Dutay, J.-C., Ethé, C., \& Gehlen, M. (2017). Variable reactivity of particulate organic matter in a global ocean biogeochemical model. Biogeosciences, 14(9), 2321-2341. http://doi.org/10.5194/bg-14-2321-201713

26Siegel, D. A., K. O. Buesseler, S. C. Doney, S. F. Sailley, M. J. Behrenfeld, and P. W. Boyd (2014), Global assessment of ocean carbon export by combining satellite observations and food-web models, Global Biogeochem. Cycles, 28, 181-196, doi:10.1002/2013GB004743.

27Stukel M.R., H. Song, R. Goericke, A.J. Miller (2017) The role of subduction and gravitational sinking in particle export, carbon sequestration, and the remineralization length 
scale in the California Current Ecosystem. Limnology and Oceanography, doi: 10.1002/lno.10636

28Omand, M.M. et al. (2015). Eddy-driven subduction exports particulate organic carbon from the spring bloom. Science 348,222-225.doi:10.1126/science.1260062.

This paper quantified the Eddy Subduction Pump (ESP) using an array of gliders in the North Atlantic during the spring bloom.

29Dall’Olmo G., J. Dingle, L. Polimene, R.J.W. Brewin and H.Claustre (2016). Substantial energy input to the mesopelagic ecosystem from the seasonal mixed-layer pump. Nature Geoscience, 9, 820-825 DOI: 10.1038/NGEO2818.

\section{This paper quantified the Mixed Layer Pump (MLP) across large regions of the high} latitude ocean.

30 Jónasdóttir S.H, Richardson K., Heath M.R. 2015. Seasonal copepod lipid pump promotes carbon sequestration in the deep North Atlantic. PNAS 112:12122-26.

\section{This paper provided the first detailed quantification of the seasonal lipid pump (SLP).}

31Weber T. et al. (2016), Deep ocean nutrients imply large latitudinal variation in particle transfer efficiency. PNAS, 113, 8606-8611.

32Marsay, C. M., R. J. Sanders, S. A. Henson, K. Pabortsava, E. P. Achterberg, and R. S. Lampitt (2015), Attenuation of sinking particulate organic carbon flux through the mesopelagic ocean, Proc. Natl. Acad. Sci. U.S.A, 112, 1089-1094.

32Giering, S. L. C., R. Sanders, A. P. Martin, S. A. Henson, J. S. Riley, C. M. Marsay, and D. G. Johns (2017), Particle flux in the oceans: Challenging the steady state assumption, Global Biogeochem. Cycles, 31, 159-171, doi: 10.1002/2016GB005424.

34Jiao N., et al. 2010. Microbial production of recalcitrant dissolved organic matter: longterm carbon storage in the global ocean. Nat. Rev. Microbiol. 8:593-599.

35Swan, B.K. et al. (2011) Potential for Chemolithoautotrophy Among Ubiquitous Bacteria Lineages in the Dark Ocean. Science, 333, 1296-1300.

36Bishop, J. K. B., M. H. Conte, P. H. Wiebe, M. R. Roman, and C. Langdon (1986), Particulate matter production and consumption in deep mixed layers: Observations in a warm-core ring, Deep Sea Res. Part A, 33, 1813-1841.

37Dall'Olmo, G., and K. A. Mork (2014), Carbon export by small particles in the Norwegian Sea, Geophys. Res. Lett., 41, 2921-2927, doi:10.1002/2014GL059244.

38Cushman-Roisin, B. (1987). Subduction. Hawaii Univ, Dynamics of the Oceanic Surface Mixed Layer P 181-196.

39Marshall, J., Nurser, A. \& Williams, R. Inferring the subduction rate and period over the North Atlantic. J. Phys. Oceanogr. 23, 1315-1329 (1993).

40Liu, L. L., Huang, R. X., 2012. (2012). The global subduction/obduction rates: Their interannual and decadal variability. Journal of Climate, 25(4), 1096-1115.

http://doi.org/10.1175/2011JCLI4228.1 
612

613

614

615

616

617

618

619

620

621

622

623

624

625

626

627

628

629

630

631

632

633

634

635

636

637

638

639

640

641

642

643

644

645

646

647

648

649

650

651

41Pollard R. T. \& L. Regier (1990) Large variations in potential vorticity at small spatial scales in the upper ocean. Nature 348, 227-229 doi:10.1038/348227a0.

42Nurser, A., \& Zhang, J. (2000). Eddy-induced mixed layer shallowing and mixed layer/thermocline exchange. Journal of Geophysical Research Ocean, 105(C9), 21851.

43Niewiadomska, K., Claustre, H., Prieur, L., \& D’Ortenzio, F. (2008). Submesoscale physical-biogeochemical coupling across the Ligurian Current (northwestern Mediterranean) using a bio-optical glider. Limnol. Oceanogr, 53, 2210-2225.

44Estapa, M. L., D. A. Siegel, K. O. Buesseler, R. H. R. Stanley, M. W. Lomas, and N. B. Nelson (2015), Decoupling of net community and export production on submesoscales in the Sargasso Sea, Global Biogeochem. Cycles, 29, 1266-1282, doi:10.1002/2014GB004913

45Lévy, M, Klein, P. and A.-M. Treguer (2001). Impacts of sub-mesoscale physics on phytoplankton production and subduction, J. Mar. Res., 59,535-565 doi: $10.1357 / 002224001762842181$

46Nagai, T., Gruber, N., Frenzel, H., Lachkar, Z., McWilliams, J. C., \& Plattner, G.-K. (2015). Dominant role of eddies and filaments in the offshore transport of carbon and nutrients in the California Current System. J. Geophys. Res. Ocean, http://doi.org/10.1002/2015JC010889

47Karleskind, P., Lévy, M., \& Memery, L. (2011). Modifications of mode water properties by sub-mesoscales in a bio-physical model of the Northeast Atlantic. Ocean Modelling, 39, 47-60.

48Karleskind, P., Lévy, M., \& Memery, L. (2011). Subduction of carbon, nitrogen, and oxygen in the northeast Atlantic. Journal of Geophysical Research Ocean, 116(C2), C02025. http://doi.org/10.1029/2010JC006446

49Stukel, M. R. et al. (2017). Mesoscale ocean fronts enhance carbon export due to gravitational sinking and subduction. Proc. Natl. Acad. Sci. USA. 114: 1252-1257. doi:10.1073/pnas.1609435114

This paper compared the magnitude of export fluxes from the biological pump and the Eddy Subduction Pump (ESP).

50Vinogradov M.E. (1997) Some Problems of Vertical Distribution of Meso- and Macroplankton in the Ocean. Advances in Marine Biology Volume 32, 1997, Pages 1-92. https://doi.org/10.1016/S0065-2881(08)60015-2

51Steinberg D.K., and M.R. Landry (2017). Zooplankton and the ocean carbon cycle. Annu. Rev. Mar. Sci. 2017. 9:413-44

52Bianchi D., Stock C., Galbraith E.D., Sarmiento J.L. (2013). Diel vertical migration: ecological controls and impacts on the biological pump in a one-dimensional ocean model. Glob. Biogeochem. Cycles 27:487-91

53Bianchi, D., Galbraith, E. D., Carozza, D. A., Mislan, K. A. S., \& Stock, C. A. (2013). Intensification of open-ocean oxygen depletion by vertically migrating animals. Nature Geoscience, 6(7), 545. 
652 This paper used global Acoustic Doppler Current Profiler observations to constrain the 653 Mesopelagic Migration Pump.

654 54Davison, P.C., Checkley Jr., D.M., Koslow, J.A., Barlow, J., (2013). Carbon export

655 mediated by mesopelagic fishes in the northeast Pacific Ocean. Progress in Oceanography

656 116, 14-30.

657 This paper used trawl surveys and metabolic modelling to assess the export fluxes 658 mediated by mesopelagic fishes.

659 55Childress, J. J., S. M. Taylor., G. M. Cailliet and M. H. Price (1980) Patterns of growth, 660 energy utilization and reproduction in some meso- and bathypelagic fishes off Southern

661 California. Marine Biology 61, 27-40 (1980)

662 56Klevjer T. A., X. Irigoien, A. Røstad, E. Fraile-Nuez, V. M. Benítez-Barrios \& S.

663 Kaartvedt. (2016). Large scale patterns in vertical distribution and behaviour of mesopelagic

664 scattering layers. Scientific Reports, 6:19873, DOI: 10.1038/srep19873

665 57Bradford-Grieve JM, Nodder SD, Jillett JB, Currie K, Lassey KR. (2001). Potential

666 contribution that the copepod Neocalanus tonsus makes to downward carbon flux in the

667 Southern Ocean. J. Plankton Res. 23: 963- 75

668 58Kobari T, Steinberg DK, Ueda A, Tsuda A, Silver MW, Kitamura M. (2008). Impacts of

669 ontogenetically migrating copepods on downward carbon flux in the western subarctic Pacific

670 Ocean. Deep-Sea Res. II, 55:1648-60.

671 59Dam, H.G., C.A. Miller and S.H. Jonasdottir (1993) The trophic role of mesozooplankton

672 at 47N, 20W during the North Atlantic Bloom Experiment. Deep-Sea Res. II, 40, 197-212.

673 60Turner J.T. (2015). Zooplankton fecal pellets, marine snow, phytodetritus and the ocean's

674 biological pump. Prog. Oceanogr. 130:205-48

675 61Bishop, J.K.B. (1989) Regional extremes in particulate matter composition and flux:

676 effects on the chemistry of the ocean interior. W.H. Berger, V.S. Smetacek, G. Wefer (Eds.),

677 Productivity of the ocean: present and past, Dahlem Konferenzen, John Wiley \& Sons, New

678 York (1989), pp. 117-137

679 62McDonnell, A. M. P., P. W. Boyd, K. O. Buesseler (2015) Effects of sinking velocities and

680 microbial respiration rates on the attenuation of particulate carbon fluxes through the

681 mesopelagic zone. Global Biogeochemical Cycles. DOI: 10.1002/2014GB004935.

682 63Durkin, C.A., M.L. Estapa, and K.O. Buesseler (2015) Observations of carbon export by

683 small sinking particles in the upper mesopelagic. Marine Chemistry, 175, 72-81.

684 64Cavan EL, Trimmer M, Shelley F, Sanders R, (2017) Remineralization of particulate

685 organic carbon in an ocean oxygen minimum zone, Nature Communications, 8 Article 14847.

686 ISSN 2041-1723.

687 65Alldredge, A.L., Silver, M.W., (1988). Characteristics, dynamics and significance of

688 marine snow. Progress in Oceanography 20, 41-82. 
689 66Jackson, G.A. (1990) A model of the formation of marine algal flocs by physical

690 coagulation processes. Deep Sea Research Part A. Oceanographic Research Papers 37 (8),

691 1197-1211, 1990.

692 67Kiørboe, T., (2001). Formation and fate of marine snow: small-scale processes with large-

693 scale implications. Scientia Marina 65 (Suppl. 2), 57-71.

694 68Iversen, M.H., Ploug, H., (2013). Temperature effects on carbon-specific respiration rate

695 and sinking velocity of diatom aggregates - potential implications for deep ocean export

696 processes. Biogeosciences 10, 4073-4085.

697 69Ohman M.D., R. Powell, M. Picheral and D.W. Jensen (2010) Mesozooplankton and

698 particulate matter responses to a deep-water frontal system in the southern California Current

699 System J. Plankton Res. 34, 815-827.

700 70D'Asaro, E. A. et al. (2018). Ocean convergence and the dispersion of flotsam. Proceedings

701 of the National Academy of Sciences, 30, 201718453-6.

702 http://doi.org/10.1073/pnas.1718453115

703 71Briggs, N., M. J. Perry, I. Cetinic, C. Lee, E. D’Asaro, A. M. Gray, and E. Rehm (2011),

704 High-resolution observations of aggregate flux during a sub-polar North Atlantic spring

705 bloom, Deep Sea Res. Part I, 58(10), 1031-1039.

706 72Stanley R.H.R., D.J. McGillicuddy Jr. Z. O. Sandwith, H. M. Pleskow (2017)

707 Submesoscale hotspots of productivity and respiration: Insights from high resolution oxygen

708 and fluorescence sections. Deep-Sea Research I, https://doi.org/10.1016/j.dsr.2017.10.005

709 73DeVries, T., and T. Weber (2017), The export and fate of organic matter in the ocean: New

710 constraints from combining satellite and oceanographic tracer observations, Global

711 Biogeochem. Cycles, 31, 535-555, doi:10.1002/2016GB005551.

712 74Cram, J.A., T. Weber, S.W. Leung, A.M.P. McDonnell, J._H. Liang, C. Deutsch (2018),

713 The role of particle size, ballast, temperature, and oxygen in the sinking flux to the deep sea.

714 Glob. Biogeo. Cyc. https://doi.org/10.1029/2017GB005710.

715 75Bianchi D., T.S.Weber, R. Kiko, C. Deusch (2018). Global niche of marine anaerobic

716 metabolisms expanded by particle microenvironments. NGEO in press.

717 https://doi.org/10.1038/s41561-018-0081-0.

718 76Callies, J., Ferrari, R., Klymak, J. M., \& Gula, J. (2015). Seasonality in submesoscale

719 turbulence. Nature Communications, 6, 6862-9. http://doi.org/10.1038/ncomms7862

72077 Lévy, M. et al. (2012). Large-scale impacts of submesoscale dynamics on phytoplankton:

721 Local and remote effects, 43-44(C), 77-93. http://doi.org/10.1016/j.ocemod.2011.12.003.

722 78Harrison, C. S., Long, M. C., Lovenduski, N. S., \& Moore, J. K. (2018). Mesoscale effects

723 on carbon export: A global perspective. Global Biogeochemical Cycles, 32, 680-703.

724 https://doi.org/10.1002/2017GB005751

725 79Picheral, M., L. Guidi, L. Stemmann, D.M. Karl, G. Iddaoud Ghizlaine and G. Gorsky

726 (2010), The Underwater Vision Profiler 5: An advanced instrument for high spatial resolution 
studies of particle size spectra and zooplankton, Limnol. Oceanogr. Methods, 8, doi:10.4319/lom.2010.8.462.

80Johnson K. (2017). Biogeochemical sensors for autonomous, Lagrangian platforms: Current status, future directions. Autonomous and Lagrangian Platforms and Sensors ALPS II. https://alps-ocean.us/agenda/(last accessed 16 March 2017).

81Ubelmann, C. and L.-L. Fu, (2014) On the transition from profile altimeter to swath altimeter for observing global ocean surface topography. J. Atmos. Oceanic Tech., 31, 560568.

82Resplandy, L. et al. (2012). How does dynamical spatial variability impact 234Th-derived estimates of organic export? Deep Sea Res. I, 68(C), 24-45.

http://doi.org/10.1016/j.dsr.2012.05.015

83Castelvecchi, D. (2016). Can we open the black box of AI? Nature, 528, 20-23. doi:10.1038/538020a.

84Sauzède, R. et al. (2016). A neural network-based method for merging ocean color and Argo data to extend surface bio-optical properties to depth: Retrieval of the particulate backscattering coefficient. Journal of Geophysical Research-Oceans, 121(4), 2552-2571. doi:10.1002/2015jc011408.

85Landschützer, P., N. Gruber, D. C. E. Bakker, U. Schuster, S. Nakaoka, M. R. Payne, T. Sasse, and J. Zeng (2013), A neural network-based estimate of the seasonal to inter-annual variability of the Atlantic Ocean carbon sink, Biogeosciences, 10, 7793-7815, doi:10.5194/bg-10-7793-2013.

86Landschützer, P., N. Gruber, D.C.E. Bakker, and U. Schuster (2014). Recent variability of the global ocean carbon sink. Global Biogeochemical Cycles, 28(9), 927-949. doi:10.1002/2014gb004853.

87Werdell, P.J., L. I. W. McKinna, E. Boss, S. G. Ackleson, S. E. Craig, W. W. Gregg, Z. Lee, S. Maritorena, C. S. Roesler, C. S. Rousseaux, D. Stramski, J. M. Sullivan, M. S. Twardowski, M. Tzortziou, and X. Zhang, (2018), An overview of approaches and challenges for retrieving marine inherent optical properties from ocean color remote sensing. Prog. Oceanogr. 160, 186-212.

88Boyd, P.W. et al. (2005). The evolution and termination of an iron-induced mesoscale bloom in the northeast subarctic Pacific Ocean. Limnology and Oceanography 50, 18721886.

89Ohman, M.D., J.-B. Romagnan (2016) Nonlinear effects of body size and optical attenuation on Diel Vertical Migration by zooplankton. Limnol. Oceanogr. 61, 2016, 765770 .

90Powell, J.R., and M.D. Ohman (2012) Use of glider-class acoustic Doppler profilers for estimating zooplankton biomass J. Plankton. Res, 34, 563-568.

91Siegel, D. A., and W. G. Deuser. (1997). Trajectories of sinking particles in the Sargasso Sea: Modeling of statistical funnels above deep-ocean sediment traps. Deep-Sea Res. Part I Oceanogr. Res. Pap. 44: 1519-1541. doi:10.1016/S0967-0637(97)00028-9 
767 92Siegel, D. A., E. Fields, and K. O. Buesseler (2008), A bottom-up view of the biological

768 pump: Modeling source funnels above ocean sediment traps, Deep Sea Res. Part I, 55(1),

769 108-127, doi:10.1016/j.dsr.2007.10.006.

770 93Llort, J., Langlais, C., Matear, R., Moreau, S., Lenton, A., Strutton, P.G., (2018).

771 Evaluating Southern Ocean carbon eddy-pump from biogeochemical Argo floats. Journal of

772 Geophysical Research: Oceans. https://doi.org/10.1002/2017JC012861

773

774

775 


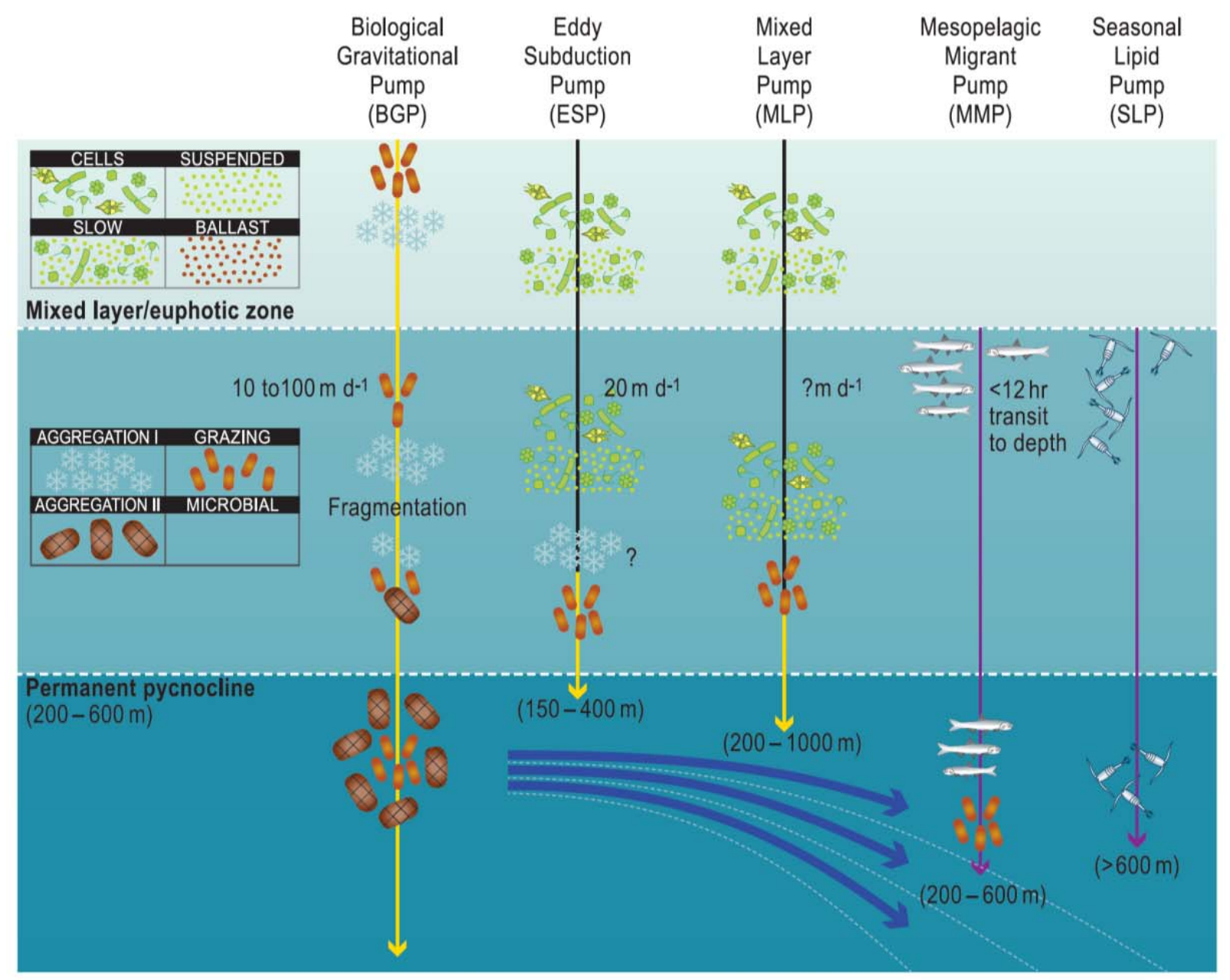

Figure 1 Interplay between particle characteristics, mode of export (BGP or PIP), delivery depth and larger scale ocean circulation for a range of pumps. In the upper panel, the box (top left) represents mixed-layer particle types, which either form large sinking particles (i.e., within the BGP, such as faecal pellets, marine snow) or are injected to depth (i.e., PIPs, suspended/ slow-settling heterogeneous particles and cells (i.e., including healthy, slow-sinking phytoplankton ${ }^{88}$ )). The vertical yellow arrow signifies the BGP; black lines physically mediated PIPs; and purple lines biologically mediated PIPs. The delivery rates of particles to subsurface strata (in $\mathrm{m} \mathrm{d}^{-1}$, ? denotes not known) are presented for each pump. Patchiness in the distribution of vertically-migrating animals (top right) plays a role in driving three-dimensional particle delivery to depth ${ }^{89,89}$, and is denoted by different fish or copepod stocks in the upper ocean. The box (middle left) presents different particle transformations central to the $\mathrm{BGP}^{12}$, but whose role is not known so far for PIPs. They include microbial solubilisation, aggregation (marine snow denoted by aggregation 1; heterogeneous faecally-dominated aggregates (aggregation II) and/or dissaggregation ${ }^{18}$ to form/break down heterogeneous particles (hatched brown symbols). In the lower panel, depths in parentheses are the reported delivery depths, with the BGP (and some PIPs) exporting some particles to the sea floor. Blue curved arrows represent transport of subsurface material along downward-sloping isopycnals (white dashed lines). Major unknowns include whether physical transport by PIPs can cause particle aggregation (signified by ? in the middle panel below subduction pump, and also applicable for the mixed-layer pump) and hence alter their mode of injection towards gravitational settling (i.e., the BGP). Other unknowns include the potential ballasting role of small mineral particles such as aerosol dust for PIPs. 

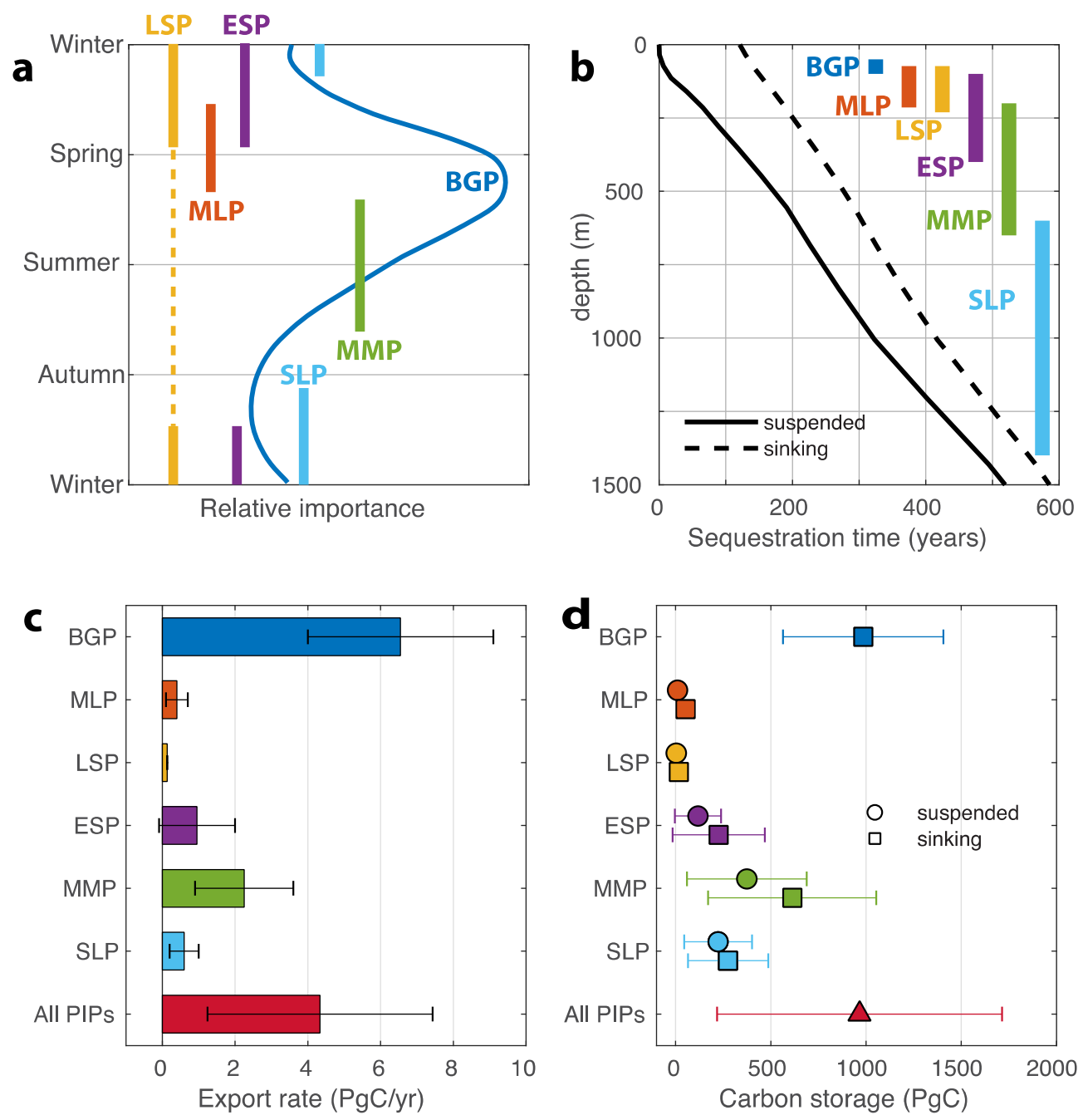

$$
\begin{aligned}
& \text { The particle injection pumps: } \\
& \text { MLP - Mixed layer pump } \\
& \text { LSP - Large-scale physical pump }
\end{aligned}
$$

$$
\begin{aligned}
& \text { ESP - Eddy subduction pump } \\
& \text { SLP - Seasonal lipid pump } \\
& \text { MMP - Mesopelagic migrant pump }
\end{aligned}
$$

Figure 2 Carbon export and storage by PIPs compared to the BGP. a) Idealised seasonality of the PIPS for regions that exhibit strong seasonality, where a Spring Bloom dominates C export by the BGP (dark blue line). Coloured bars indicate season of peak $\mathrm{C}$ export by the PIPs (acronyms defined in legend). Note the large-scale physical pump should be strongest when mixed layers are deepest, but is likely operative all year (dashed line). b) Sequestration efficiency of the PIPs. Black lines represent the global-mean sequestration timescale for carbon injected at a given depth, defined as the time for remineralised carbon to circulate back to the ocean surface, computed in a data-constrained circulation model (see S-Methods). Solid line assumes that particles are suspended, so remineralisation occurs at the injection depth, whereas dashed line assumes that particles are sinking and remineralise over depth (see Methods). Colored bars show injection depth range of the BGP and PIPs. The efficiency of each pump is defined as the sequestration time from its injection depth. c) Strength of the pump mechanisms, defined as their rate of carbon export or injection (see Table S1). "All PIPs” refers to the sum of the five individual PIPs d) Ocean carbon storage by each pump, defined as the product of the strength (c) and efficiency (b). Two scenarios are shown for each PIP, using the sequestration time for suspended (circles) and sinking (square) particles, whereas the BGP is assumed to export only sinking particles. For the sum of PIPs, we present a "most likely" scenario, in which the migrant pump injects sinking particles (faecal pellets), and all other PIPs inject suspended particles (triangle). 

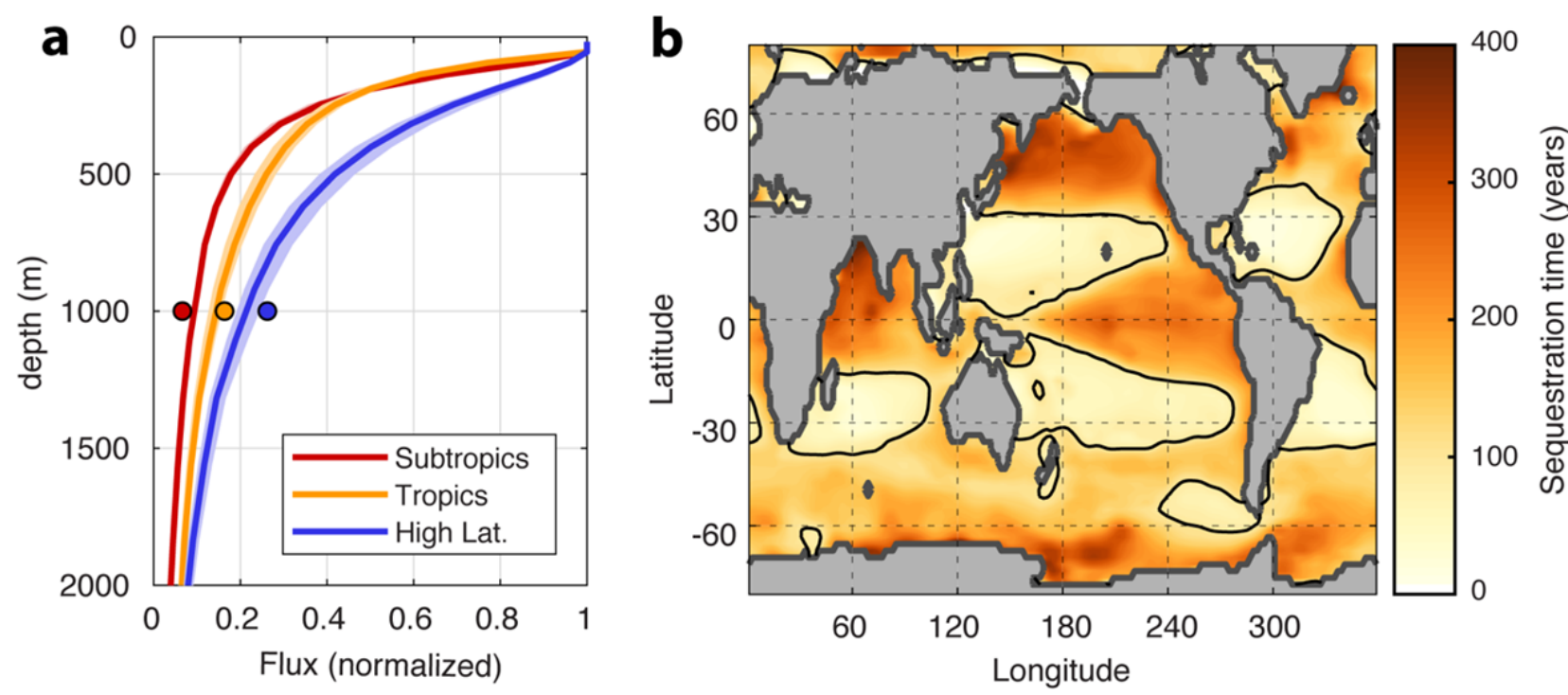

Figure 3. Fate of exported organic matter constrained in models from geochemical remineralisation tracers. a) Organic matter flux over depth (normalised to flux at the base of the euphotic zone), averaged across subtropics, tropics, and high latitude regions (as defined ${ }^{31}$ ). Lines show flux profiles from a mechanistic model ${ }^{73}$ that is optimised to match geochemical constraints (shading represents the range between 12 model configurations); circles represent the transfer efficiency diagnosed directly from nutrient accumulation in an ocean circulation model ${ }^{31}$. b) Sequestration time of exported carbon. The spatial pattern reflects both variability in the particle flux attenuation (a), and patterns of large-scale circulation. The thin black lines separates regions of efficient ( $>100$ years) and inefficient ( $<100$ years) carbon sequestration. 


\section{Box 1 Approaches used to investigate downward particle export, from the BGP to PIPs.}

The BGP is quantified in a biologically-patchy upper ocean (green filaments) using ship-based surface sampling (particle production) and subsurface particle interception by sediment traps, most recently neutrally-buoyant traps downstream of particle source regions (orange instruments, a). This coupled surfacesubsurface sampling strategy is logistically-complex, temporally- and spatially-restricted (i.e., represented here by a "statistical funnel”"1,92, see a), and hence provides a ' $1 \mathrm{D}$ ' view of particle export that is extrapolated to the basin scale using satellite observations and/or modelling. This ' $1 \mathrm{D}$ ' viewpoint cannot measure the PIPs presented in b) to e), and is contrasted in a) with the $4 \mathrm{D}$ view ${ }^{29,93}$ obtained by an ensemble of BGC-Argo floats (white instruments).

(b) the mixed-layer pump, in which particles are detrained when the pycnocline (blue dashed line) shallows, can been addressed regionally through backscattering (a proxy for POC) profiles measured by BGC-Argo floats $^{36}$, or globally using satellite surface-ocean backscattering and Argo/BGC-Argo (density/backscattering) vertical profiles $^{32}$. c) the seasonal lipid pump is quantified using surveys of overwintering copepods at depths below the permanent pycnocline and subsequent scaling of their lipid-enriched biomass in carbon content $^{33}$. d) the eddy subduction pump can been quantified using gliders (pink instruments) and subsequent modelling ${ }^{31}$, BGC-Argo floats (bio-optics/oxygen/physics) ${ }^{93}$ or surveys based on multiple POC profiles in conjunction with coupled models (regional circulation/particle dynamics) ${ }^{30,49}$. e) quantification of the mesopelagic migrant pump (active diel transport of carbon by mid-water biota, denoted by moon and sun symbols) requires mid-water trawl surveys along with metabolic modelling ${ }^{54,55}$. Some multidisciplinary studies $^{30,31,49}$ have combined these approaches to cross-compare export flux from the BGP (green arrows (d)) and the eddy subduction pump (purple arrows represent subsurface particle maxima recorded at the eddy periphery $^{31}$ ). Note, the large-scale subduction pump ${ }^{23}$ is not presented here.

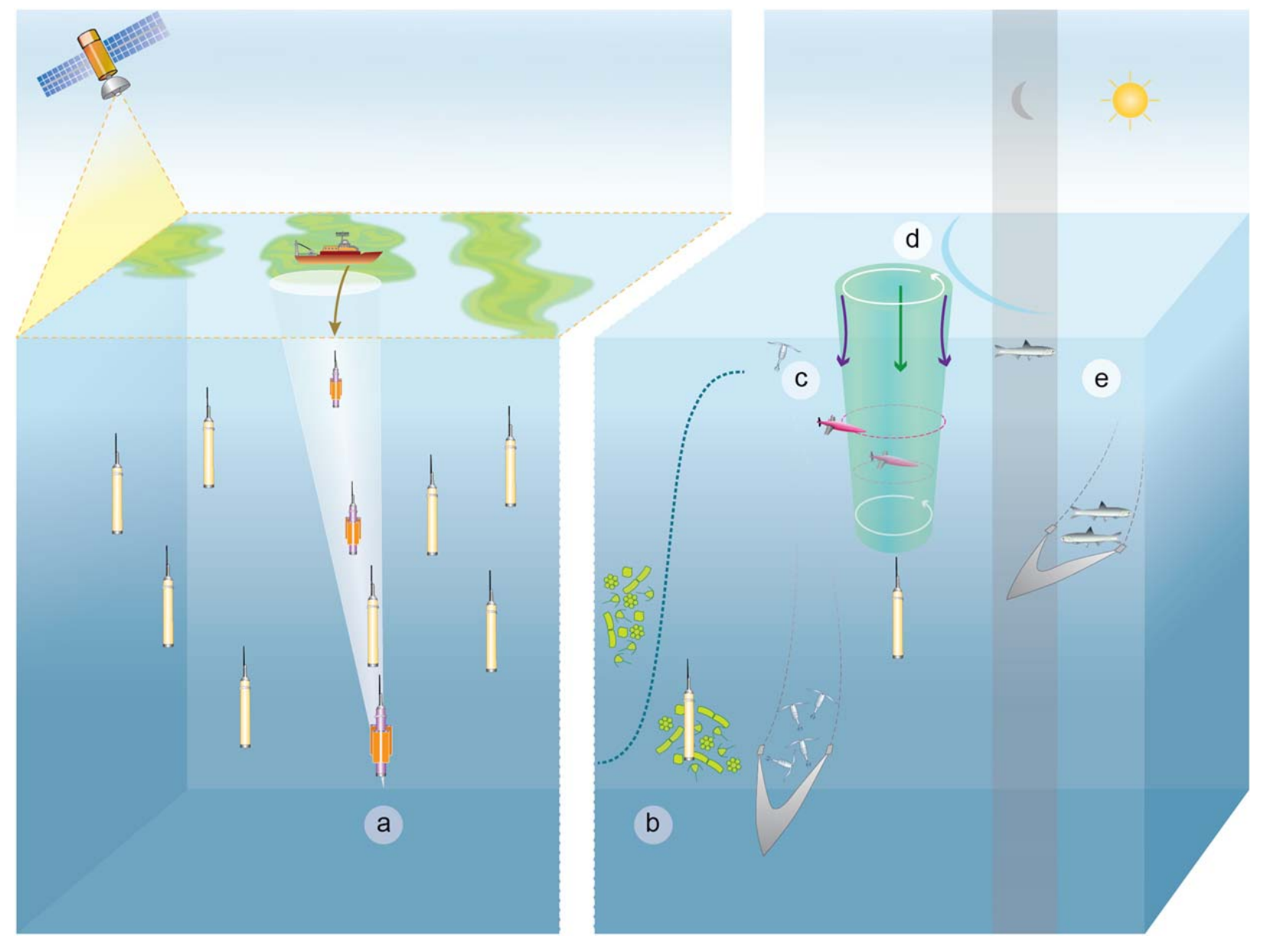

